\title{
The complex act of projecting oneself into the future
}

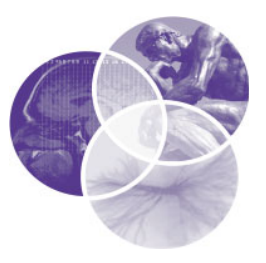

Stanley B. Klein*

Research on future-oriented mental time travel (FMTT) is highly active yet somewhat unruly. I believe this is due, in large part, to the complexity of both the tasks used to test FMTT and the concepts involved. Extraordinary care is a necessity when grappling with such complex and perplexing metaphysical constructs as self and time and their co-instantiation in memory. In this review, I first discuss the relation between future mental time travel and types of memory (episodic and semantic). I then examine the nature of both the types of self-knowledge assumed to be projected into the future and the types of temporalities that constitute projective temporal experience. Finally, I argue that a person lacking episodic memory should nonetheless be able to imagine a personal future by virtue of (1) the fact that semantic, as well as episodic, memory can be self-referential, (2) autonoetic awareness is not a prerequisite for FMTT, and (3) semantic memory does, in fact, enable certain forms of personally oriented FMTT. () 2012 John Wiley \& Sons, Ltd.

How to cite this article:

WIREs Cogn Sci 2013, 4:63-79. doi: 10.1002/wcs.1210

\section{INTRODUCTION}

$\mathrm{A}$ 11 organisms capable of long-term memory necessarily are oriented toward the future. ${ }^{1}$ A feature of memory possibly unique to humans, however, is complexity and temporal range of futureoriented imaginings (for reviews, see Refs 2-5). The more complex, flexible, and temporally extensive our future-oriented mentation, the more purposeful and proactive our responses can be to our environment. ${ }^{5,6}$ By virtue of this sophistication, our species can both anticipate and plan for future contingencies that transcend our current needs and motivational states. ${ }^{2,4,6}$ From an adaptive standpoint, a capacity to imagine and plan for one's personal future (especially plans not tied to current drives and needs), based, in large part, on memory of past circumstances and contingencies, confers an enormous selective advantage on its possessor.

Memory is a system created by natural selection: ${ }^{7,8}$ It exists in its present form because that arrangement solved certain recurrent problems faced by the organism in its evolutionary past (memory,

*Correspondence to: Klein@psych.ucsb.edu

Department of Psychological and Brain Sciences, University of California, Santa Barbara, Santa Barbara, CA, USA as will become clear as this review proceeds, is best conceived not as a system, but rather as a set of functionally independent, though normally interacting, systems). Evolution does not produce new, complex, metabolically costly phenotypic systems by chance. $^{9,10}$ Such systems acquire their functional organization because they contributed to the organism's ability to survive and reproduce. ${ }^{10,11}$ An evolved system, defined with respect to functionality, consists in those component processes-and their coordinated interactions-necessary to accomplish specific adaptive tasks. For an organism to behave more appropriately (i.e., more adaptively) at a later time because of experiences at an earlier time, the organism must be equipped not only with mechanisms that retrieve ontogenetically acquired information. Many features of human memory have been designed by evolution to interface with systems for long-term anticipation and planning. ${ }^{7,12}$

Evidence of memory-based planning in the human lineage dates back hundreds of thousands of years. Archeological and historical investigations leave little doubt that our ancestors organized hunting parties, created and transported tools (sometimes a considerable distance), buried their dead, provided supplies for an afterlife and organized agrarian 
societies which, in turn, served as the foundation for subsequent development of cities, states, and nations. ${ }^{3,13-16}$ Much of human mental life and its cultural products-norms, written and material resources, symbolic representation, abstract thought, science, religion, social complexity-derives from our capacity to orient toward, and plan with respect to, an uncertain but potentially controllable future. In fact, Klein et al. ${ }^{6}$ have proposed that it is possible that memory enabled humans, over the course of evolutionary history, to be aware of the future before we were able to consciously experience the past. Regardless of whether that proposal turns out to be correct, an understanding of the inherently futureoriented nature of information processing is essential for understanding the functional properties of human memory.

In this paper, I first review the history of psychological investigations into the human ability to mentally travel into the future (i.e., future-oriented mental time travel; hereafter FMTT). I then address three of the key 'players' in this ability-that is, memory, self, and subjective temporality-with the goals of (1) explicating their causal roles in FMTT, as well as (2) clarifying their conceptualizations in the context of FMTT.

I conclude that, compared to the largely descriptive work that characterized early forays into FMTT, psychological science has made considerable advances in the past two decades. However, much remains to be done with regard to the conceptual sophistication of our constructs and appreciation of their roles in enabling the multiplicity of types of subjective temporalities that make up the category of FMTT.

\section{REVIEW OF RESEARCH ON FMTT}

The earliest known Western writing to relate subjective temporality and memory dates from the 8th Century BC. In his Theogony, Hesiod contends that the ability to transcend objective time is made possible by the faculty of human memory. An opposing view, voiced by Aristotle (384-322 BC) in his classic study of memory, De Memoria, makes it clear that 'the object of memory is the past' (cited in Ref 17, p. 13). The future, by contrast, is not known by memory but rather by acts of anticipation.

The Aristotelian position dominated intellectual discourse on the relation between time and memory for the next two millennia. Thus we find Augustine of Hippo (354-430 AD) arguing: 'The time of present things past is memory, the time of present things present is direct experience and the time of present things future is expectation.' (Confessions, Book 11, chapter 20, heading 26). ${ }^{a}$ Although Monastic authorities of the Middle Ages proposed various emendations of the concept of memory, its relation to the past served as a stable resting place for discourse.

By the 18th century, conditions were falling into place for a loosening of the Aristotelian grip on the connection between memory and the past. The scientific revolution was sweeping through Europe and soon became a leading force for cultural change. Scientific explanation began to overshadow and replace philosophical and theological 'truths' that had dominated continental thought for nearly two millennia (though often with considerable opposition). By the 19th century, science, with its promise that the future was more important than the past, rapidly was becoming the prevailing cultural weltanschauung. ${ }^{18}$

It was not until the late into the 19th century that memory was accorded the status of an object of scientific inquiry. In 1887, Bradley, ${ }^{19}$ influenced by Darwin's landmark principles of natural selection, adopted a stance contrary to the one which had dominated the intellectual landscape for nearly 2000 years. In contrast to previous concern with saddling memory to a particular temporal location (i.e., past, future) he proposed-in keeping with an evolutionary agenda-a more functional analysis. His thesis, in agreement with Hesiod (though likely for different reasons), held that memory must, of adaptive necessity, be oriented toward the future.

\begin{abstract}
'Why is our memory directed towards our incoming sensations and towards the (temporal) side from which change comes? ... The answer, in a word, is practical necessity ... Life being a process of decay and of continual repair and struggle throughout against dangers, our thoughts, if we care to live, must mainly go the way of anticipation. We are concerned practically with what meets us and what we go to meet, and this practical concern has formed the main habit of our thought.' (Bradley, pp. 581-582, Ref 19; word in parentheses added for textual clarification).
\end{abstract}

For much of the next century, discussion of the relation between memory and future-oriented temporal experience remained mostly in the province of philosophy, while mainstream psychological work on memory and time was devoted largely to its more intuitive relation to the past. Some psychologists, however, did take an interest in what might be termed 'future orientation'- that is, the manner in which an individual's thought about, or orientation toward, the future influences their behavior-albeit 
with little regard to possible mechanisms (memorial or otherwise) underpinning the human ability to imagine the nonexistent future. This work, whose beginnings trace to the early 1950s (for reviews, see Refs 20,21) examined a diversity of topics such as the part played by future-orientation on life-span development, ${ }^{22,23}$ delinquent behavior, ${ }^{24,25}$ emotions, ${ }^{26}$ impulse control, ${ }^{27-29}$ motivation, ${ }^{30}$ academic achievement, ${ }^{31}$ and mental illness. ${ }^{32,33}$ Most, if not all, this work treated future-oriented thought as a variable which people might use or be affected by. Influenced by hard-line positivism's informal ban on black-box psychology (i.e., behaviorism), the cognitive and neural underpinnings of future-orientation seldom figured in the discussion.

All that changed in the mid-1980s when Endel Tulving ${ }^{34}$ observed that patient K.C. (then called N.N., or No Name) - a man evidencing complete retrograde and anterograde episodic amnesia-not only was unable to recall his personal past, but also was unable to imagine his future. Around this time, two conceptually sophisticated, though, of necessity, somewhat speculative papers on the role of memory in future-oriented thought (largely consistent with Tulving's empirical observations) were published by Ingvar. ${ }^{35,36}$ The empirical observations and theoretical work provided by Tulving and Ingvar represents the origins of our 'modern' interests in the relation between memory and the ability to orient toward and imagine the future.

It was not until 1996 however, that the relation between memory and FMTT began to take the form of what would become a major growth-industry in psychology. Research commenced at a modest pace, but over the last 5 years (2007-2012) there has been a 10 -fold increase in investigative activity, with more than 80 publications from that period on display. In addition to cognitive and neuroscientific research on FMTT, personality and social psychology, which had not devoted much attention to the topic since the late 1970s, also evidenced renewed fascination with mental time travel. For example, in 2012 a special issue of the European Journal of Social Psychology was devoted exclusively to questions pertaining to the topic.

Before discussing this body of work (which constitutes the main body of this paper), I briefly mention four key publications that appeared in 1996 and 1997 which set the stage for much of what followed. Two conceptual treatments ${ }^{4,37}$ offered sophisticated theoretical, empirically informed, analysis of the role of episodic memory in future-oriented personal projection. And two studies of individuals suffering varying degrees of episodic impairment ${ }^{38,39}$ demonstrated the patients not only had difficulty remembering their personal past but also had trouble imagining their personal future.

The next step in explicating the relation between memory and the future was taken by Klein and his colleagues in 2002. ${ }^{40}$ Their patient, D.B., whose episodic deficits were comparable in severity to those of K.C., provided evidence for a dissociation between type of memory and type of temporality. As anticipated from previous work, ${ }^{34,38}$ D.B. showed an inability to recollect events from his personal past as well as to project himself into the future. By contrast, the relation between his semantic memory (largely intact ${ }^{41}$ ) and FMTT revealed the opposite pattern: D.B. could both remember nonpersonal events and imagine nonpersonal future scenarios.

Klein and colleagues drew two general conclusions from this study. First, the classic dissociation between semantic and episodic memory for facts and personally experienced events could be replicated when an episodically impaired patient was asked to imagine the future. Second, the relation between memory and future-orientation could not be captured by a single type of temporal subjectivity. As D.B. (and, as we will see, more recent studies) showed, the type of temporality one experiences appears to depend, at least in part, on the type of memory required by task demands: Tasks that encourage episodic projection (e.g., 'What do you think will you eat for lunch today?') promote a form of temporal projection that enables one to position oneself in the future (Klein and colleagues termed this 'lived time'). By contrast, tasks relying for their performance on semantic knowledge appeared to promote impersonal (that is, public) forms of temporal projection. Klein and colleagues termed this 'known time' (e.g., 'In the next 10 years the environment will face the following challenges').

These temporal divisions drew inspiration from McTaggart's ${ }^{42}$ partition of temporality into two basic types: Temporality experienced as a constant flow from future to present to past, with the temporal designators continually changing ontological status (e.g., what once was future now is present, what once was present now is past, etc.) and temporal experience as a fixed, earlier-later (or before-after) chronology in which temporal placement of an event is invariant (e.g., April 4th, 1982 is, and always will be, prior to April 4th, 1983). Klein and colleagues presumed that the former maps to 'lived time' while the latter captures what they termed 'known time' (as will be discussed in the section titled Types of Subjective Temporality', these distinctions are too crude to do sufficient explanatory work). Around the same time, a theoretical treatment by Atance and 
O'Neill ${ }^{43}$ voiced similar conclusions about the roles of the roles of episodic and semantic memory in FMTT. The empirical basis for their presumption of the possibility of semantic future thought drew, in large part, on evidence made available by the case of D.B.

These empirical findings and theoretical insights led Klein, Cosmides, Tooby, and $\mathrm{Chance}^{7}$ to propose-in the spirit of Bradley's evolutionarily grounded intuitions - that:

'The adaptive function of information storage is intrinsically prospective: It is used to support future decisions and judgments, which cannot be known in advance with certainty. To the extent that the character of subsequent decisions and judgments can be predicted, the memory system can be tailored to flag relevant information and precompute variables that are required to make them.' (emphasis added: Klein, Cosmides, Tooby, and Chance, p. 313, Ref 7).

While this now may seem obvious, keep in mind that prior to the $1990 \mathrm{~s}$, research investigating the relation between time and memory focused almost exclusively on memory's orientation to the past (prospective memory being the obvious exception; e.g., Ref 44). For example, in the volume Time and Memory, ${ }^{45}$ only approximately 13 of more than 400 pages examining the relation between memory and time were devoted to memory's role in imagining or thinking about the future.

\section{THE DOMINANCE OF THE EPISODIC MEMORY MODEL OF FMTT: 'ONE-SIZE-FITS-ALL'}

As the relation between memory and future-oriented thought became more widely appreciated, theoretical, and empirical papers began to appear at an impressive rate. This work dealt almost exclusively with the role of a particular type of memory-episodic-in FMTT. One possible explanation for this restrictive focus on the type of memory involved-with two notable exceptions-Atance and $\mathrm{O}^{\prime} \mathrm{Neill}^{43}$ and Klein et al. ${ }^{40}$-previous research and theory had examined only the effects of episodic memory ${ }^{10,37}$ and its impairment. ${ }^{34,38}$ Under these circumstances, researchers with a developing interest in FMTT simply may have overlooked the possibility that different types of memory contribute to futureoriented temporal experience. Regardless, only a part of the intricate relation between memory and FMTT was being addressed.

Investigations of the role of episodic memory in FMTT were impressive both in their quantity and diversity. They included-but were not limited to-its neural correlates, ${ }^{46-53}$ developmental progression, ${ }^{54-56}$ evolutionary implications, $4,6,57,58$ the specificity and detail of imagined scenarios, ${ }^{39,46,59,60}$ narrative ability, ${ }^{52}$ relation to imagined thoughts of others, ${ }^{61}$ personal well-being, ${ }^{62}$ and neurological status-for example, amnesia, $40,51,52,56,59,63$ Alzheimer's disease, ${ }^{64}$ schizophrenia, ${ }^{65}$ and depression. ${ }^{39,66,67}$ For most of the past decade investigative attention remained fixed on the episodic component of long-term memory. Terms such as 'episodic future thought' ${ }^{53,60,68-70}$ 'episodic simulation/construction', ${ }^{46,63,71}$ 'episodic selfprojection', ${ }^{49}$ and 'episodic foresight' ${ }^{57,72,73}$ became the lingua franca of the field.

However, review papers published toward the end the first decade of the 21st century began to voice concern over possibility that episodic exclusivity might be an unnecessary constraint on full appreciation of the memorial underpinnings of FMTT. Specifically, by 2007, a number of theoretical treatments of FMTT voiced concerns-based largely on evolutionary and conceptual considerations-about the wisdom of a purely episodic approach. ${ }^{5,70,73-75}$ Thus, Suddendorf and Corballis ${ }^{5}$ argue 'Construction of future and past episodes both depend in parts on semantic memory...' (p. 302). But, for the most part, empirical support for this position did not begin to appear with any frequency until 2011.

Worries over the explanatory adequacy of the episodic memory approach to FMTT also were expressed by investigators encountering difficulty framing their findings within the context of the episodic model. ${ }^{50,76-78}$ For example, patients with developmental episodic amnesia (as a result of hippocampal damage) sometimes retained the ability to imagine future experiences (Refs 59,78; but see Ref 56). Explanations adhering largely to the episodic model argued that these patients possessed residual hippocampal function that could support futureprojection. ${ }^{59,78}$ However, these findings also are consistent with the possibility that both episodic and semantic memory support FMTT. It thus remained a live question whether semantic memory by itself, or in interaction with partially intact episodic function (inferred from residual hippocampal activity), supported future-oriented imagination found in these studies.

\section{SEMANTIC MEMORY RETURNS TO THE REALM OF THE POSSIBLE}

Empirical support for the opinion that FMTT cannot be understood solely in terms of episodic 
memory ${ }^{71,74-76}$ recently has been demonstrated by several labs. I already have discussed the work of Klein and colleagues ${ }^{40}$ with patient D.B. More recent evidence comes from Irish et al., ${ }^{79}$ who showed that individuals suffering semantic dementia (with corresponding impairment of semantic memory) had difficulty constructing novel future scenarios despite largely intact episodic function. The authors concluded that semantic memory is a necessary component of future-oriented thought. Consistent with these findings, Duval et al. ${ }^{80}$ showed that patients experiencing early to moderate stages of semantic dementia experience impaired future-oriented selfprojection future regardless of whether the task performed was designed to access semantic or episodic memory. Taken together, these findings suggest that semantic memory not only is sufficient for FMTT (at least for certain forms). It may be necessary as well.

Additional support for semantic FMTT comes from the case of patient J.R., who, following surgical treatment for temporal lobe epilepsy showed preserved episodic function alongside selective impairment of semantic memory. ${ }^{81}$ Unlike the dementia patients studied by Duval et al., ${ }^{80} \mathrm{~J} . \mathrm{R}$. was able to recall the personal past and imagine a personal future. However, his impersonal future thinking seriously was impaired in both temporal directions from the present. In combination with findings from patient D.B., this case suggests the possibility of a double dissociation between type of memory (episodic and semantic) and the ability to imagine types (personal and nonpersonal) of future scenarios.

Studies performed with nonmemory impaired individuals also have begun to erode the sustainability of a purely episodic model of FMTT. For example, it now has been shown that the ability to construct future-oriented simulations of novel events requires contributions from both episodic and semantic memory. ${ }^{77}$ Along similar lines, work by D'Argembeau and colleagues ${ }^{69,82}$ demonstrates that thinking about oneself in the future draws on personal resources from both semantic and episodic memory. And Viard et al. ${ }^{83}$ have demonstrated that healthy adults rely on both episodic and semantic resources to envision future events.

In a study specifically designed to examine the brain areas associated with personal and nonpersonal future thought (which the authors align with episodic and semantic memory, respectively), Abraham et al. ${ }^{84}$ found no brain regions that selectively activated for nonpersonal future thinking. However, a problem drawing conclusions from this research is that the authors' choice of self-referential tasks does not permit clear inferences about the memory systems (semantic and episodic) underlying self-referential experience (for discussion of the difficulties involved in drawing inferences about the type of memory systems supporting self-referential task performance, see Ref 85).

\section{Evolutionary, Developmental, and Ethological Support for the Semantic Contributions to FMTT}

As mentioned, a focus on the episodic component of future-oriented mental projection limited appreciation of the complexities of FMTT. Thus far I have discussed the memorial implications of this overly restrictive analysis. I turn now to the unintended consequences of an exclusively episodic model for making sense of evolutionary, ethological and developmental findings and theory.

Nonhuman animals have been hypothesized to lack episodic memory (Refs 34,86,87; but see Ref 88). An implication of this argument is that if an episodic model of mental time travel is correct, then the ability to engage in FMTT is uniquely human. $., 5,34$ Nonhuman animals, lacking episodic memory, are, of conceptual necessity, unable to engage in any form of mental time travel ${ }^{89,90}$ : They are subjectively stuck in the present. ${ }^{91}$ Similar limitations in subjective temporality have been held to apply to children prior to the age of 4 -the time at which episodic abilities are assumed to take on a more adult-like function. 4,92-95

However, philosophical, ${ }^{96}$ evolutionary, ${ }^{6,57,58}$ and ethological considerations, ${ }^{88,97-100}$ as well as developmental research, ${ }^{101-104}$ call into question the validity of the proposed constraints on temporal perspective. For example, work by Clayton and her colleagues have shown that scrub jays appear capable of hiding food in a manner that strongly suggests an appreciation of future contingencies and personal needs (for review, see Ref 88).

Given current limitations in our knowledge of the ability of nonhuman animals to anticipate and plan for future states of its organism and environment, it is prudent to restrict consideration to animals with well-developed central nervous systems (Escherichia coli and yeasts would thus fail to meet this requirement). There are important differences between acts that can be characterized as 'anticipation' and the neurocognitive representational states they engender. Anticipatory behaviors in primitive beings are likely to be largely reflexive, unaccompanied by the representational states and intentionality we associate with more advanced forms of planning. However, since evolution builds on existing adaptations, ${ }^{10}$ these primitive anticipatory responses very well may have 
served as part of the neural scaffolding that eventuated in the more sophisticated forms of planning on evidence in mammals, reptiles, avian and other highly evolved species.

With these caveats in place, it follows that since information processing is inherently prospective, ${ }^{7,19,105}$ an inability to anticipate and plan for future contingencies would be an evolutionary dead-end for animals that depend for their survival (and hence reproductive success) on such fitnessenhancing adaptations. Clearly, this is not the case. As noted, all organisms capable of long-term memory are, of adaptive necessity, oriented toward the future. What distinguish adult humans from other animals and young children are not temporal projective abilities, per se, but rather the sophistication of these abilities: The anticipatory and planning skills of adult humans are more complex, flexible and temporally extensive, and thus can be more purposeful and proactive in response to the environment. ${ }^{2,6} \mathrm{By}$ virtue of this sophistication, our species, unlike others, can anticipate and plan for future contingencies in a manner that transcends current needs and motivational states (Refs 5,6, but see Ref 106). Indeed, an entire subfield of human memory research is predicated on the assumption that the ability to plan for future contingencies is so essential that memory exhibits special mnemonic capacities when oriented toward future-oriented survival concerns. ${ }^{107-109}$

An evolved capacity to imagine and plan for future contingencies confers an enormous selective advantage on its possessor. ${ }^{6,57,58,109}$ To require animals-human or otherwise-to navigate their worlds absent anticipatory abilities would be to render them extinct by definitional fiat. More to the point, such a presumption is inconsistent with research on both young children and nonhuman beings. ${ }^{73,88,96,102,104-106}$

While it may seem that the types of temporal orientation discussed in this section comprise a different category of temporal thought from that taken as the object of most current FMTT investigations, this prejudice is neither logically nor empirically supportable. I address this issue-that is, the diversity of experiences that qualify as forms of future-oriented temporal projection-later in this review.

\section{Summing up Types of FMTT and Types of Memory}

In a review of recent findings on the role of episodic memory in FMTT, Addis and Schacter ${ }^{76}$ observed:

'Although amnesics may generate fewer episodic details relative to controls, they sometimes show little or no reduction in the number of semantic details comprising their event narratives ... It also has been shown in other studies that patients with episodic, but not semantic, memory deficits can successfully complete future thinking tasks that are based primarily on general knowledge' (e.g., nonpersonal future tasks; Klein et al., p. 9, Ref 7).

I concur with these sentiments. However, I take things a bit farther. First, while episodic memory unambiguously participates in some types of FMTT, ${ }^{40,81}$ it appears to be neither a necessary nor sufficient condition for many of the forms of FMTT (e.g., anticipation, simulation, foresight, personal continuity, etc.) thus far examined (for a related view, see Ref 75$).^{b}$ Patient populations with known episodic deficits (e.g., autistic ${ }^{110}$ ) have been found to possess the ability to anticipate the future welfare of others ${ }^{111}$ as well as complete tasks requiring simulation of future-oriented events. ${ }^{112} \mathrm{In}$ the latter case, patient performance was statistically equivalent to that of nonautistic controls. Moreover, analysis revealed that a substantial portion of the material generated during future-oriented simulation was from semantic memory. ${ }^{112}$ Finally, MartinOrdas et al. ${ }^{72}$ recently reviewed the phenomenon of episodic foresight in young children and concluded that semantic memory likely plays an important role, although precise specification of its contributions awaits further research.

However, since these studies examine individuals with partially functioning episodic abilities, their findings cannot rule out a role for episodic memory (a similar concern applies to patients manifesting selective or partial semantic impairments). More compelling, therefore, are data obtained from the small subset of amnesic patients (D.B. and K.C.) who evidence complete absence of episodic recollection ${ }^{40,113}$ yet still can engage in forms of FMTT (the FMTT abilities displayed by these patients is described below). These findings, considered in conjunction with those of patients suffering more limited episodic impairment (e.g., autism ${ }^{112}$ ) or largely intact episodic function (e.g., semantic dementia79) offer strong support for the argument that although episodic memory contributes some types of future imaginings, it is neither necessary nor sufficient for a variety of FMTT manifestations.

Second, recent research also supports the proposal that semantic memory is both necessary and, in many cases, sufficient for future-oriented projections of both personal ${ }^{113,114}$ and impersonal ${ }^{40,81}$ mental time travel. For example, patient K.C., despite lacking an ability to imagine himself in the future, ${ }^{34}$ nonetheless could make personally relevant 
future-oriented decisions. ${ }^{113}$ And, patient D.B, despite complete absence of episodic recollective ability, was able to imagine future-oriented public scenarios. ${ }^{40}$ In contrast, impairments of semantic memory (coupled with intact episodic function) can wreak havoc on a patient's ability to engage in certain forms FMTT. ${ }^{79,80 c}$

Logical considerations also suggest that resources in semantic memory may be necessary for the subjective temporality (e.g., the ability to represent a time as a concept whose constituent identities-past, present, and future-are in a constant state of change; the ability to represent two-place relations between the variables such as 'earlier' and 'later', as well as relations such as temporal transitivity). Moreover, as recent empirical treatments have demonstrated ${ }^{77}$ and conceptual analyses have concluded, ${ }^{54,75,76}$ semantic knowledge (often in the form of generalized scripts) likely provides the conceptual scaffolding necessary to construct novel, future-oriented "episodic" scenarios.

At a minimum, semantic knowledge appears necessary ${ }^{79,80}$ and possibly sufficient ${ }^{79,80,113}$ for the successful performance of a wide range of futureoriented tasks. In contrast, the episodic system does not need to be functional for an individual to engage in a number of forms of FMTT.

Interestingly, it may turn out to be the case that semantic memory, rather than episodic memory, is the key component of the vast majority of future-oriented mental abilities. While these considerations clearly are not conclusive, I do think they (1) demonstrate that the challenges facing a purely episodic model of FMTT are quite severe, and (2) suggest ways in which we can achieve a more empirically warranted and theoretically satisfying understanding of the relation(s) between FMTT and the memory systems involved.

\section{FMTT: BEYOND THE EPISODIC/SEMANTIC DISTINCTION}

While it now is clear that semantic memory contributes in a variety of ways to FMTT, ${ }^{40,69,75,77,79-81,114}$ new work suggests we may need to further widen our conceptual net to capture the neurocognitive complexity of FMTT. For example, Zeithamova et al. ${ }^{115}$ have suggested that in addition to memory, other cognitive systems (e.g., perceptual) are involved in the ability to successfully plan for future contingencies. Similar sentiments are found in de Vito et al. ${ }^{116}$ who argue that executive function plays a crucial role in Parkinson's patients' successful performance on future thinking tasks. Arzy et al. ${ }^{117}$ have shown that brain areas associated with mental imaging must be taken into account for some forms of FMTT. And, discussing their work with children age 4 and under, Suddendorf and his colleagues contend that the human capacity for foresight depends, to an important degree, on cognitive abilities that fall outside the domain of memory proper. ${ }^{104}$

These data appear to be telling us that full appreciation of FMTT requires we expand the scope of our investigations beyond the type of memory systems assumed causally efficacious and acknowledge that other neurocognitive systems play a role in our ability to orient toward the future. ${ }^{5,75,76}$ And, as we saw in the case of memory, these other systems are not unitary either in their composition or in their effects on FMTT. With this in mind, I turn to next consideration of two core 'other' constituents of FMTT—subjective temporality and the self. ${ }^{40,71,118}$

\section{TYPES OF SUBJECTIVE TEMPORALITY}

As noted, a conceptual limitation of many early studies of FMTT was that investigators frequently treated temporal experience as though it were a unitary construct. It is not. Beginning with McTaggart; ${ }^{42}$ (though related ideas stretch back to antiquity ${ }^{119}$ ) these have been seen as two dominant, ${ }^{d}$ nonreducible, types of subjective temporality. ${ }^{120-122}$ One (which McTaggart called the A-series) views time as the flowing of events from future to present to past. In this scheme, events continually change temporal identity-that which once was future becomes present and that which is present will, with time's flow, recede further into the past. A second view (the Bseries) conceptualizes temporality as a set of static relations between events: Events pre-exist in temporal association (running 'earlier' to 'later') and thus never change positions: ${ }^{123}$ Time is frozen into an unchanging pattern of 'before and after'. ${ }^{120,121,124}$

Drawing on these ideas, Klein et al. ${ }^{40}$ argued that the type of temporality experienced in FMTT takes one of two forms: 'lived' and 'known'. The former, corresponding to McTaggart's A-series, enables a person to experience time as a moving present. This was held to be the time of episodic recollection. ${ }^{4,6,93}$ Accordingly, it seldom is experienced prior to age $4 .{ }^{92,94,95,125}$

By contrast, 'known time' draws on McTaggart's B-series. It consists in chronological knowledge, enabling one to know about events and their fixed temporal relations (e.g., before and after). This form of temporality, supported by semantic memory, enables pre-episodic children and nonhuman animals to anticipate and plan for future contingencies, ${ }^{5,6}$ as well as to learn relations between cause and effect. ${ }^{13}$ 
However, as I hope has been made apparent, Klein et al.'s ${ }^{40}$ proposed correlation between types of temporal subjectivity and systems of memory is too simple to capture the richness of temporal experience. As documented in the historical review section of this paper, there is a diversity of forms of subjective temporality enabling a person to project him or herself into the future-including, but not limited to-mental simulation, scenario construction, forecasting, self-continuity (i.e., personal diachronicity), foresight, anticipation, and planning (for reviews, see Refs 20,21,126,127). McTaggart's A and B series can be seen as basic categories of subjective temporality, ${ }^{e}$ each supporting a subset of specific temporal experiences. ${ }^{f}$

While each type of future-oriented temporality can (sometimes with considerable effort) be mapped onto either the A or the B series, each has its own neurocognitive properties that enable distinct forms of subjective temporal experience. ${ }^{73,74,118}$ FMTT consists in a complex set of instances that manifest themselves in multiple ways: each enables a conceptually, experientially, and empirically distinct form of temporal experience. Accordingly, FMTT is unlikely to submit to analysis in terms of one, or a few, underlying mechanisms.

We need to be more nuanced about what it is that we refer to when we use the term FMTT. Is it our ability to construct personal future scenarios, to construct public future scenarios, to plan for future contingencies, to anticipate events, our sense of personal continuity, our ability to make future-oriented judgments, predict our future feelings, attitudes and beliefs? Absent a firm conceptual grounding, the term FMTT becomes a 'catch-all' that masks the fact that different forms of subjective temporality, each with their own set of partially overlapping neurological constituents, play a role in the different tasks we use to probe our ability to orient toward the future.

\section{TYPES OF SELVES: A CASE FOR MULTIPLICITY AND FOR THE POSSIBILITY OF PERSONAL FMTT BASED ON KNOWLEDGE OF SELF IN SEMANTIC MEMORY}

The evidence presented likely has left the impression that, in the vast majority of cases, FMTT based on semantic memory is limited to the construction of nonpersonal scenarios. ${ }^{40,84}$ Such a restriction, as noted, would have dire consequences for an animal's chances for survival: It is essential to be able not only to imagine $a$ future, but to imagine a future in which one is an agent. ${ }^{18,128,129}$ The diversity and success of nonhuman species-dating back several billion years-suggests semantic-based future self-projection not only is possible but may be normative (at least in organisms with sufficient neural complexity to engage in representational forms of mental time travel).

For example, humans lacking all access to episodic memory can experience FMTT of a personal, agentive nature. There are a number of reasons this should not be surprising. First, despite initial belief that semantic memory lacked a self-referential component, ${ }^{130,131}$ it now is well known that semantic memory stores information about one's self (Refs 132-137; for review see Refs 138,139). Self-referential semantic memory includes, but is not limited to, facts about one's life (e.g., name, occupation, favorite foods; Refs 135,139,140), personal goals ${ }^{69}$ personal attitudes, ${ }^{141}$ a sense of personal diachronicity ${ }^{141-144}$ and knowledge of one's personality. ${ }^{145 g}$

Accordingly, episodic impairment, even cases sufficiently severe to cover a person's entire life, does not render the person necessarily incapable of imagining or anticipating his or her future. Consider again patient D.B. Cognizant of his cognitive deficits, he expressed frequent concern for his personal future. ${ }^{146}$ That is, he saw himself as a person who existed in the present and would continue to exist in the future: He had a clear sense of being a temporal continuant. This diachronic personal knowledge, of neurological necessity, must have been derived largely from his intact corpus of semantic self-knowledge. ${ }^{139,140,146}$

A similar conclusion can be drawn from the case of H.C., a young woman who suffered severe episodic amnesia as a result of congenital loss of bilateral hippocampal function. None-theless she was able to generate plausible, futureoriented self-referential scenarios. ${ }^{114}$ The investigators concluded that since her performance could not be attributed to hippocampal function, it likely was the result of preserved knowledge contained in semantic memory. And a recent investigation of patient K.C. demonstrated that his ability to make future-oriented personally-relevant decisions was preserved despite his complete lack of access to episodic memory. ${ }^{113}$ Clearly, at least some forms of future-oriented selfprojection draw on resources in semantic memory.

In short, the type of self-knowledge recruited for personal projection into the future admits to variety of instantiations. This is because self-knowledge resides both in episodic and semantic memory. Moreover, within a particular memory system, several different, functionally dissociable, aspects of self have been identified (for recent reviews, see Refs 140,143,145). 
Accordingly, the specific manner in which memory is interrogated plays a critical role in whether future-oriented semantic FMTT will be public or personal. ${ }^{40,71,84,114}$ To date, most investigations of FMTT have involved scenarios and simulations designed (at least a priori) to draw on material from episodic memory. However, when one takes into account that (1) there are multiple forms of FMTT, (2) self-knowledge can be episodic and semantic, and (3) the manner in which a FMTT task is constructed plays a critical role in determining the type of self/memory contributions elicited, the possibility for semantic FMTT of a self-referential and personal nature transitions from a theoretical possibility to an empirical certainty.

\section{FMTT and the Autonoetic/Noetic Awareness Hypothesis}

One reason for the widely held assumption that episodic and semantic memory differ with respect to the type of temporal awareness they enable $37,49,68,69,80,93,147$ may be Tulving's influential distinction between types of memory and types of subjective temporal experience. On this view, episodic memory enables autonoetic awareness, while semantic memory enables a type of awareness he terms noetic. ${ }^{34,86,87,118,135,148}$ Autonoetic awareness is defined as 'self-knowing': When autonoetically aware, the individual is held to focus awareness on his or her own subjective experience. Autonoetic remembering is also characterized by '.. a unique awareness of reexperiencing here and now something that happened before, at another time and in another place' (Tulving, p. 68; Ref 148).

By contrast, noetic awareness occurs when one thinks objectively about something one knows. 3,6 Individual are said to be noetically aware 'when they retrieve general information in the absence of a feeling of re-experiencing the past' (Spuznar, p. 144; Ref 75). Accordingly, 'Only 'autonoetic consciousness' is thought to bear a personally meaningful relation to time' (Szpunar \& Tulving, ${ }^{118}$ p. 4).

Autnoetic and noetic awareness align naturally with episodic and semantic modes of remembering, respectively. ${ }^{34,148}$ Moreover, only autonoetic memorial experience is assumed capable of providing the phenomenal requirements for mental time travel (see also Ref 4). Accordingly, the self of episodic memory is tied directly to temporally rich autonoetic experience. By contrast, the experience of semantic knowledge (i.e., noetic) is a mode of experiencing lacking subjective temporality. These considerations may help explain the focus on the role played by episodic memory in FMTT.
It is widely recognized that the autonoetic hypothesis does good work when applied to experience of the past. It is unclear, however, whether (or how) this ability transfers to experience of the future. Most psychologists and philosophers agree that there is 'something it is like' to re-experience past events. But, is this experience required for a future-oriented imagining? Certainly one cannot 'relive' or 'reexperience' an as-yet nonexistent set of circumstances (whether personal or public). Although an autonoeticFMTT connection has intuitive appeal (both reliving the past and imagining the future are, after all, forms mental time travel), there are serious metaphysical, epistemological, and experiential differences between past experience and future imaginings (for review, see Refs 149-152). Beyond intuition and stipulation, what are the causally or logically necessary conditions that link autonoetic awareness to future temporal experience? It is far from obvious that conceptual considerations alone can support the importation of autonoetic principles across temporal boundaries.

If logical analysis cannot do the needed work, perhaps empirical evidence can justify an intrinsic connection between episodic memory and autonoetic future-directed experience. So, does relevant empiricism exist? Yes-but it is not entirely supportive.

Take, for example, the case of Zasetsky, a Russian soldier in WWII. ${ }^{153}$ As a result of battle, he suffered massive neural damage to areas controlling higher cortical functions such as the analysis, synthesis, and organization of complex associations. $\mathrm{He}$ was aphasic, perceptually and proprioceptively disoriented, hemianopic, densely episodically amnesic (both antrograde and retrograde) though he maintained (heavily compromised) semantic function. According to Luria, Zasetsky struggled to piece together the fragments of a once clear sense of identity and self-understanding with only the slimmest of cognitive resources available to him. Eventually, under the extraordinarily patient tutelage of Luria and others, Zasetsky slowly and painfully regained a rudimentary ability to read, write, and perform basic bodily functions. Consequently, he was able to provide Luria with a record of his thoughts and feelings.

Although there are many remarkable aspects of this case study, I focus on one with direct relevance to the presumed relation between autonoetic selfprojection and episodic memory. Despite Zasetsky's monumental loss of access to epistemological bases of self-knowledge (both episodic and, to a lesser degree, semantic), he exhibited both an ability and a desire to plan for his personal future. He was aware of his deficits and greatly troubled by their effects on his ability to place himself physically, temporally, and 
spatially. Yet, and this is the key point, he was not stuck in the present. He had clear goals designed to improve his personal misfortune and consciously expressed an unambiguous motivation to carry them forward. In the end, it was this subjectively felt determination to live a better life that led Zasetsky to undertake an arduous rehabilitative program that enabled him to regain partial contact with the external world and aspects of self-knowledge rendered temporarily unavailable to subjective awareness. In short, while he often professed an inability consciously to place himself in a specific future circumstance, he was not stuck in the 'now'. The future was selfreferential, it was a subjective reality which embodied the potential fruition of the personal goals he took such heroic measures to achieve.

Consider next the case of patient R.B. R.B. suffered a very rare form of amnesia in which his episodic memory came loose from its self-referential moorings: ${ }^{154}$ R.B. was able to relive personally experienced events, yet was unable to experience those events as his own! He maintained both the content and the mode of episodic memory experience, but had lost direct awareness that these experiences were his (for a related case, see Ref 155). He could, of course, infer from the content of the experiences that they must be his, but direct feeling of the 'mineness' of his episodic experience was lacking (similar coming apart of ownership and content of experience often is found in cases of schizophrenia; Ref 156).

With respect to FMTT, R.B. had no difficulty forming highly detailed, often personal, plans despite the separation of personal ownership and personal content. ${ }^{146,154}$ Thus, while R.B. maintains access to episodic self-referential content, this content has broken free of its autonoetic moorings and thus cannot present itself to itself (i.e., self-reflexively). One possibility is that his intact semantic-self provided both the necessary content and a personal grounding. Regardless of whether this explanation is viable, the fact remains that R.B. could imagine a personal future despite severely compromised autonoetic abilities. ${ }^{b}$

Taken together with the findings from patients K.C., D.B., and H.C., these cases suggest that the connection between types of memory and types of temporal awareness is considerably more complicated than often envisioned. ${ }^{i}$ The stipulation that only episodic memory enables one to project oneself into the future might seem a profitable way to align types of memory experience with subjective temporality. The empirical evidence, however, is not entirely cooperative. Rather, research supports the following provisional conclusion: Semantic memory, whether in the presence of partially or fully impaired episodic memory, enables an individual to imagine a personal future, ${ }^{114}$ make future-oriented personal judgments and plans ${ }^{113,153,154}$ and have a sense of oneself as a temporal continuant. ${ }^{142-144,146}$

\section{Summing Up}

Given what we now know about self-referential nature of both episodic and semantic memory, it appears unjustified to assume that semantic-based FMTT tasks are restricted knowledge in the public domain. McTaggart's ${ }^{42} \mathrm{~A}$ and B temporal series certainly do not require such asymmetry: The $\mathrm{A}$ and $\mathrm{B}$ series both appear capable of supporting future-oriented self-awareness. ${ }^{120,121,157}$ Nor, contra Klein et al. ${ }^{40}$ do personal and nonpersonal future projections map in any simple manner onto specific systems of memory.

If experimental tasks are constructed to encourage a person to (1) imagine, anticipate or plan for the future (or focus on scenarios requiring personal temporal continuance), and (2) utilize the specific types of self-knowledge represented in semantic memory, there is no reason why semantically based future imaginings cannot be self-referential. Realization of these possibilities is found in a number of recent investigations. ${ }^{82,113,114,154}$

\section{CONCLUSIONS AND CONSIDERATIONS}

FMTT is an extremely complex and perplexing, yet important, ability. ${ }^{1,5-7,58,71,76,118}$ It confers on its owner a capacity to imagine and prepare for the 'now and the next'. Although the present review describes some of the conceptual and empirical progress achieved in explicating this essential function, much work remains.

A full understanding of FMTT requires appreciation of the incredible complexity of the undertaking. Broadening our conceptual appreciation of the 'key players' in future-oriented subjectivity is needed on several levels. The type of memory supporting FMTT is not restricted to episodic function: Semantic memory also supports forms of mental time travel. ${ }^{40,76,114}$ Indeed, it would be surprising if (unlike most longterm memory activity) episodic and semantic memory did not jointly contribute to future temporality.

Second, subjective temporality takes a variety of forms (e.g., planning, anticipation, goals, forecasting, projection, diachronicity, imagined scenarios). Though likely related either to the A and B temporal series, specific instances sharing category membership are not obviously reducible, one to the other, and thus affect FMTT in highly individualized 
ways. Specific forms of temporality can be personal or public, self-referential, other-referential, or even object-referential. There is no one necessary connection between types of subjective temporality and type of memory.

The self-the presumed agent and focus of most FMTT investigations-consists in a multiplicity of representations contained both in episodic and semantic memory. ${ }^{85,132,135,139,140,145}$ Accordingly, the finding that personal forms of temporal projection entail self-referential activity does not license conclusions about the specific system of memory mediating self-referential temporal experiences. ${ }^{85}$

Finally, given the complexity of the factors involved, task construction is likely to play a major role in determining which conclusions about the factors enabling FMTT are warranted. ${ }^{158}$ This particularly is true of studies examining the neural correlates of FMTT. ${ }^{159}$ Given the number and variety of processes involved in the multiplicity of subjective experiences categorized as FMTT, it will be essential for brain imaging studies to be vigilant with regard to conceptual and empirical considerations justifying their assumptions about the psychological referents of neural activation. ${ }^{160,161}$ Until the perplexing, multifaceted relation between the self, subjective temporality and memory is better understood, activation in the hippocampus-or elsewhere in the brain-does not license strong inferences about which type(s) of memory (or of self, or of temporality) are correlated with neural activity.

The task of explicating FMTT is extraordinarily difficult. This is to be expected of any endeavor that takes as its subject matter two of the most complex and contentious metaphysical questions capable of being addressed-self and time. Although memory may be seen by some ${ }^{162}$ to be a relatively research-friendly target of investigation, reflection on its nature-that is, a system that makes possible the mental representations of self and time-suggests assumed tractability simplifies the issues involved greatly. ${ }^{18}$

While the magnitude and complexity of the topics addressed in this review is daunting, progress is being made. That progress, as I see it, derives mostly from an increased appreciation of the complexity of the undertaking. By contrast, much of the empirical evidence currently on hand has conceptual and definitional ambiguities that make it hard to be certain what our findings are telling us. As Heisenberg ${ }^{163}$ points out, learning the right questions to ask of nature is often more than halfway to the solution of a problem. And knowing what one is looking for is a precondition for finding those answers.
Despite concerns, it is essential not to be discouraged by what, at present, appears to me an extraordinarily difficult problem accompanied by a somewhat untidy set of findings. We should not be disheartened by lack of clear answers in a field of research whose current incarnation is very recent, and whose topics embody among the deepest metaphysical mysteries. Understanding the conditions that enable a person to project him or herself into a 'nonexistent' future is among the most conceptually complex, but important questions we can ask. As Danziger (Ref 18; p. 21) sagely observes, opening windows to shed light on difficult topics 'is likely to bring advantages when compared to a life behind shutters, even if the view outside is somewhat limited and distorted'.

Any headway we make will have immense relevance to our appreciation of what it means to be human. FMTT resides at the heart of what enables our species to have progressed to a point of cultural, social, intellectual, moral, technological and scientific sophistication unparalleled by life on our planet.

\section{NOTES}

${ }^{a}$ The author wishes to thank Liliann Manning and her colleagues whose excellent historical research brought to my attention the views of both Hesiod and St. Augustine on the relation between time and memory.

${ }^{b}$ This argument obviously trades on acceptance of the idea that FMTT cannot be construed as a unique or single form of subjective awareness. Instead, it is best characterized as a category consisting in a diverse collection of types of subjective temporalities that constitute its specific instances. This multiple realizability conception will be discussed later in this review.

${ }^{c}$ The finding that patients lacking episodic memory ${ }^{34,40}$ cannot imagine a personal future (but, see Refs $113,114)$, suggests that certain tasks preclude semantic time travel into the personal future. It does not, however, warrant the conclusion that, absent episodic memory, all forms of FMTT are rendered unavailable. For example, personal diachronicity-the sense that one is a temporal continuant-is a form of FMTT that does not require the availability of any episodic recollective ability. ${ }^{146}$ More on this later.

${ }^{d}$ In fact, McTaggart ${ }^{42}$ suggests additional temporal systems (what he terms 'series'; e.g., the C and D series). However, these conceptualizations either can be show to be conceptually incoherent or they collapse into the $\mathrm{A}$ or $\mathrm{B}$ series $^{120}$. 
${ }^{e}$ Note that there is considerable discussion among philosophers concerning whether the A and B series are both necessary (for review, see Refs 120,122) or even whether the experience of temporality is an illusion. ${ }^{123}$ These concerns, while the subject of considerable debate, will not be discussed here.

${ }^{f}$ Although some have suggested that the A series is self-centered (or episodic) and that the B series is observer independent (or semantic; Ref 118), such mappings are not obvious. These time series are, after all, subjective, not objective temporal instantiations: They require a subjective presence to make them 'real' (e.g., the fact that 1993 came after 1983 has no consequence unless there is someone to represent that fact). As such, both the A and B series cease to hold any meaning unless they constitute part of someone's conceptual reality (additional support for these assertions will be presented in the next section).

${ }^{g}$ Given this intermixing of memory systems and forms of self-knowledge, it often is difficult to be certain whether a particular self-referential task is drawing on knowledge contained in episodic or semantic memory. ${ }^{85}$ This becomes relevant to the present discussion when one realizes that investigators often equate personal (i.e., self-referential) forms of time travel with episodic memory and nonpersonal forms with semantic memory content (i.e., nonselfreferential; Refs 40,84,117). Dividing the conceptual pie in this manner invites confusion between types of temporal experience and types of memory-based self-knowledge.

${ }^{b}$ Of course, it remains a fact that patients such as K.C. and D.B. were consciously unable to imagine themselves engaging in certain future activities (e.g., 'what will you do tomorrow?'). However, my position is not that autonoetic future-oriented projection is unrelated to episodic memory. My point is that if such a connection can be shown to exist, it will be relational, rather than intrinsic, to that system.

${ }^{i} \mathrm{~A}$ number of the arguments advanced in this review draw on data from patients suffering varying degrees of amnesia. While this may appear to be a limitation with regard to generality, it does have the merit of putting hypotheses to the test in a context in which the episodic and semantic components of memory performance can be relatively-well pried apart. Specifically, when participants have access to both episodic and semantic memory, it is difficult to rule out interplay between the two systems in the performance of experimental tasks and therefore difficult to compellingly demonstrate their respective contributions to task performance (for discussion, see Refs 41,140).

Amnesic patients, by contrast, provide a particularly effective method for testing the functional independence of semantic and episodic memory because these patients typically display intact semantic memory with impaired access to episodic memory (or, less commonly, intact episodic memory in the presence of semantic impairment). Therefore, it is possible with amnesic patients to test semantic memory contributions to FMTT with reasonable assurance that episodic memory is not involved (and vice versa).

However, interpretation of the data from amnesic patients requires caution. A now compromised, but once functioning, memory system may still drive rudimentary capacities. For example, the finding that an amnesic patient still is capable of semantic prospection need not entail that the same semantic prospection is possible by an infant or an animal that does not have episodic capacities. Suddendorf and Corballis, ${ }^{5}$ for instance, argued that humans increasingly use semantic prospection as they get older, but that this dovetails on a fundamental episodic ability: 'Predictions can increasingly be made by abstract rules (i.e., using semantic prospection) rather than through imagination of individual future events. Retaining details of individual events becomes less important the more over-arching principles have been deduced. Good prediction depends on the right balance of semantic and episodic information.' (Ref 5, p. 312).

So interpretation of the neuropsychological cases presented, at least as far as conclusions about evolution and development are concerned, requires awareness of the limits of its applicability. However, as I hope this review has demonstrated, most of my conclusions with respect to FMTT do not rest exclusively on data from patients with neural dysfunction.

\section{ACKNOWLEDGMENTS}

The author wishes to thank Dan Schacter for his sage observations and insights. The comments of Michael Corballis, Thomas Suddendorf and an anonymous reviewer also contributed greatly to the ideas expressed in this article. 


\section{REFERENCES}

1. Klein SB. Future mental time travel: types of memory, types of selves and types of temporality. Social Cogn. In press.

2. Bischof-Koehler D. On the phylogeny of human motivation. In: Eckensberger LH, Lnatermann ED, eds. Emotion and Reflexivitaet. Vienna: Urban \& Schwarzenberg; 1985, 3-47.

3. Donald M. Origins of the Modern Mind: Three Stages in the Evolution of Culture and Cognition. Cambridge, MA: Harvard University Press; 1991.

4. Suddendorf T, Corballis MC. Mental time travel and the evolution of the human mind. Genet Social Gen Psychol Monogr 1997, 123:133-167.

5. Suddendorf T, Corballis MC. The evolution of foresight: what is mental time travel, and is it unique to humans? Behav Brain Sci 2007, 30:299-313.

6. Klein SB, Robertson TE, Delton AW. Facing the future: memory as an evolved system for planning future acts. Mem Cogn 2010, 38:13-22.

7. Klein SB, Cosmides L, Tooby J, Chance S. Decisions and the evolution of memory: multiple systems, multiple functions. Psychol Rev 2002, 109:306-329.

8. Sherry DF, Schacter DL. The evolution of multiple memory systems. Psychol Rev 1987, 94:439-454.

9. Dawkins R. The Selfish Gene. Oxford: Oxford University Press; 1976.

10. Williams GC. Adaptation and Natural Selection: A Critique of Some Current Evolutionary Thought. Princeton, NJ: Princeton University Press; 1966.

11. Barkow JH, Cosmides L, Tooby J, eds. The Adapted Mind: Evolutionary Psychology and the Generation of Culture. New York, NY: Oxford University Press; 1992.

12. Suddendorf T, Busby J. Making decisions with the future in mind: developmental and comparative identification of mental time travel. Learn Motiv 2005, 36:110-125.

13. Dunbar R. Grooming, Gossip, and the Evolution of Language. Cambridge, MA: Harvard University Press; 1996.

14. Gibson KR, Ingold T, eds. Tools, Language, and Cognition in Human Evolution. New York: Cambridge University Press; 1993.

15. Johnson DM. How History Made the Mind: The Cultural Origins of Objective Thinking. Chicago, IL: Open Court.; 2003.

16. Mumford L. Technics and Civilization. New York, NY: Harcourt; 1934.

17. Sorabji R. Aristotle on Memory. Providence, RI: Brown University Press; 1972.

18. Danziger K. Marking the Mind: A History of Memory. Cambridge: Cambridge University Press; 2008.
19. Bradley FH. Why do we remember forwards and not backwards? Mind 1887, 12:579-582.

20. Cottle TJ, Klineberg SL, eds. The Present of Things Future: Explorations in the Human Experience of Time. London: Collier Macmillan Publishers.; 1974.

21. Gorman BS, Wessman AE, eds. The Personal Experience of Time. New York, NY: Plenum Press.; 1977.

22. Klineberg SL. Changes in outlook on the future between childhood and adolescence. J Person Social Psychol 1967, 2:185-193.

23. Wohlford P. Extension of personal time, affective states, and expectation of personal death. J Person Social Psychol 1966, 3:559-566.

24. Brandt RJ, Johnson DM. Time orientation in delinquents. J Abnorm Social Psychol 1955, 51:343-345.

25. Davids A, Kidder C, Riech M. Time orientation in male and female juvenile delinquents. J Abnorm Social Psychol 1962, 64:239-240.

26. Melges FT, Fougerousse CE. Time sense, emotions, and acute mental illness. J Psychiat Res 1968, 4: $127-140$.

27. Klineberg SL. Future time perspective and the preference of delayed reward. J Person Social Psychol 1968, $8: 253-257$.

28. Rozek F, Wessman AE, Gorman BS. Temporal span and delay of gratification as a function of age an cognitive development. J Genet Psychol 1977, 131:37-40.

29. Siegman AW. The relation between future time perspective, time estimation, and impulse control in a group of young offenders and in a control group. J Counsel Psychol 1961, 25:470-475.

30. Nuttin J. Future Perspective and Motivation. Hillsdale, NJ: Lawrence Erlbaum Publishers; 1985.

31. Teahan JE. Future time perspective, optimism, and academic achievement. J Abnorm Social Psychol 1958, 57:379-380.

32. Krauss HH, Ruiz RE. Anxiety and temporal perspective. J Clin Psychol 1967, 23:340-342.

33. Wallace M. Future time perspective in schizophrenia. J Abnorm Social Psychol 1956, 52:240-245.

34. Tulving E. Memory and consciousness. Canad Psychol(Psychologie Canadienne) 1985, 26:1-12.

35. Ingvar DH. 'Memory for the future': an essay on the temporal organization of conscious awareness. Hum Neurobiol 1985, 4:127-136.

36. Ingvar DH. Hyperfrontal distribution of the cerebral grey matter flow in resting wakefulness: on the functional anatomy of the conscious state. Acta Neurol Scand 1979, 60:12-25.

37. Wheeler MA, Stuss DT, Tulving E. Toward a theory of episodic memory: the frontal lobes and autonoetic consciousness. Psychol Bull 1997, 121:331-354. 
38. Dalla Barba G, Cappelletti JY, Signorini M, Denes G. Confabulation: remembering 'another' past, planning 'another' future. Neurocase 1997, 3:425-436.

39. Williams JMC, Ellis NC, Tyers C, Healy H, Rose G, MacLeod AK. The specificity of autobiographical memory and imageability of the future. Mem Cogn 1996, 24:116-125.

40. Klein SB, Loftus J, Kihlstrom JF. Memory and temporal experience: the effects of episodic memory loss on an amnesic patient's ability to remember the past and imagine the future. Social Cogn 2002, 20:353-379.

41. Klein SB, Rozendal K, Cosmides L. A social-cognitive neuroscience analysis of the self. Social Cogn 2002, 20:105-113.

42. McTaggart JME. The unreality of time. Mind 1908, 68:457-484

43. Atance CM, O’Neill DK. Episodic future thinking. Trends Cogn Sci 2001, 5:533-539.

44. Brandimonte M, Einstein GO, McDaniel MA, eds. Prospective Memory: Theory and Applications. Mahwah, NJ: Erlbaum; 1996.

45. Hoerl C, McCormack T, eds. Time and Memory: Issues in Philosophy and Psychology. Oxford: Clarendon Press; 2001.

46. Addis DR, Cheng T, Roberts RP, Schacter DL. Hippocampal contributions to the episodic simulation of specific and general future events. Hipросатрus 2011, 21:1045-1052.

47. Addis DR, Wong AT, Schacter DL. Remembering the past and imagining the future: common and distinct neural substrates during event construction and elaboration. Neuropsychologia 2007, 45:1363-1377.

48. Botzung A, Denkova E, Manning L. Experiencing past and future personal events: functional neuroimaging evidence on the neural basis of mental time travel. Brain Cogn 2008, 66:202-212.

49. Buckner RL, Carroll DC. Self-projection and the brain. Trends Cogn Sci 2007, 11:49-57.

50. Cooper JM, Vargha-Khadem E, Gadian DG, Maguire EA. The effect of hippocampal damage in children on recalling past and imagining new experiences. Neuropsychologia 2011, 49:1843-1850.

51. Hassabis D, Kumaram D, Vann DS, Maguire EA. Patients with hippocampal amnesia cannot imagine new experience. Proc Natl Acad Sci 2007, 104: 1726-1731.

52. Race E, Keane MN, Verfaellie M. Medial temporal lobe damage causes deficits in episodic memory and episodic future thinking not attributable to deficits in narrative construction. J Neurosci 2011, 31: 10262-10269.

53. Szpunar KK, Watson JM, McDermott KB. Neural substrates of envisioning the future. Proc Natl Acad Sci 2007, 104:642-647.
54. Addis DR, Wong AT, Schacter DL. Age-related changes in episodic future simulation for future events. Psychol Sci 2008, 19:33-41.

55. Busby J, Suddendorf T. Recalling yesterday and predicting tomorrow. Cogn Dev 2005, 20:363-372.

56. Kwan D, Carson N, Addis DR, Rosenbaum RS. Deficits in past remembering extend to the future in a case of developmental amnesia. Neurospychologia 2010, 48:3179-3186.

57. Boyer P. Evolutionary economics of mental time travel. Trends Cogn Sci 2008, 12:219-224.

58. Suddendorf T, Addis DR, Corballis MC. Mental time travel and the shaping of the mind. Phil Trans Royal Soc B 2009, 364:1317-1324.

59. Mullally SL, Hassabis D, Maguire EA. Scene construction in amnesia: an fMRI study. J Neurosci 2012, 32:5646-5663.

60. Szpunar KK, McDermott KB. Episodic future thought and its relation to remembering: evidence from ratings of subjective experience. Conscious Cogn 2008, 17: 330-334.

61. Spreng RN, Grady CL. Patterns of brain activity supporting autobiographical memory, prospection and theory of mind, and their relation to the default mode network. J Cogn Neurosci 2009, 22:1112-1123.

62. Philippe LP, Koestner R, Beaulieu-Pelletier G, Lecours S, Lekes N. The role of episodic memories in current and future well-being. Person Social Psychol Bull 2012, 38:505-519.

63. Schacter DL, Addis DR, Buckner RL. Remembering the past to imagine the future: the prospective brain. Nature Rev Neurosci 2007, 8: 657-661.

64. Addis DR, Sacchetti DC, Ally BA, Budson AE, Schacter DL. Episodic simulation of future events is impaired in mild Alzheimer's disease. Neuropsychologia 2009, 47:2660-2671.

65. D’Argembeau A, Raffard S, Van der Linden. Remembering the past and imagining the future in schizophrenia. J Abnorm Psychol 2008, 117:247-251.

66. Dalgleish T, Hill E, Golden AJ, Morant N, Dunn BD. The structure of past and future lives in depression. J Abnorm Psychol 2011, 120:1-15.

67. Sarkohi A, Bjarehed J, Andersson G. Links between future thinking and autobiographical memory specificity in major depression. Psychology 2011, 2: $261-265$.

68. Atance CM, O'Neill DK. The emergence of episodic future thinking in humans. Learn Motiv 2005, $36: 126-144$

69. D’Argembeau A, Mathy A. Tracking the construction of episodic future thoughts. J Exper Psychol Gen 2011, 140:258-271.

70. Schacter DL, Addis DR. The cognitive neuroscience of constructive memory: remembering the past and 
imagining the future. Phil Trans Royal Soc B 2007, 362:773-786.

71. Hassabis D, Maguire EA. Deconstructing episodic memory with construction. Trends Cogn Sci 2007, 11:299-306.

72. Martin-Ordas G.Atance CM, Louw A. The role of episodic and semantic memory in episodic foresight. Learn Motiv. In press.

73. Suddendorf T. Episodic memory versus episodic foresight: similarities and differences. WIREs Cogn Sci 2009, 1:99-107.

74. Schacter DL, Addis DR, Buckner RL. Episodic simulation of future events: concepts, data, and applications. Ann New York Acad Sci 2008, 1124:39-60.

75. Szpunar KK. Episodic future thought: an emerging concept. Perspect Psychol Sci 2010, 5:142-162.

76. Addis DR, Schacter DL. The hippocampus and imaging the future: where do we stand? Front Hum Neurosci 2012, 5:article 173.

77. Anderson RJ. Imagining novel futures: the roles of event plausibility and familiarity. Memory 2012, 20:443-451.

78. Maguire EA, Vargha-Khadem F, Hassabis D. Imagining fictitious future experiences: evidence from developmental amnesia. Neuropsychologia 2010, 48:3187-3192.

79. Irish M, Addis DR, Hodges JR, Piguet O. Considering the role of semantic memory in episodic future thinking: evidence from semantic dementia. Brain 2012, 135:2178-2191.

80. Duval C, Desgranges B, de La Sayette V, Belliard S, Eustache F, Piolino P. What happens to personal identity when semantic knowledge degrades? A study of the self and autobiographical memory in semantic dementia. Neuropsychologia 2012, 50:254-265.

81. Manning L, Denkova E, Unterberger L. Autobiographical significance in past and future public semantic memory: a case study. Cortex. Submitted for publication.

82. D'Argembeau A, Lardi C, Van der Linden M. Selfdefining future projections: exploring the identity function of thinking about the future. Memory 2012, 20:110-120.

83. Viard A, Desgranges B, Eustache F, Piolino P. Factors affecting medial temporal lobe engagement for past and future episodic events: an ALE meta-analysis of neuroimaging studies. Brain Cogn 2012, 80:111-125.

84. Abraham A, Schubotz RI, von Cramon Y. Thinking about the future versus the past in personal and nonpersonal contexts. Brain Res 2009, 1233:106-119.

85. Klein SB. Self, memory, and the self-reference effect: an examination of conceptual and methodological issues. Person Social Psychol Rev 2012, 16:283-300.
86. Baddeley A, Aggleton JP, Conway MA. Episodic Memory: New Directions in Research. Oxford: Oxford University Press; 2002.

87. Tulving E. Episodic memory: from mind to brain. Ann Rev Psychol 2002, 53:1-25.

88. Clayton NS, Russell J. Looking for episodic memory in animals and young children: prospects for a new minimalism. Neuropsychologia 2009, 47:2330-2340.

89. Roberts WA, Feeney MC. The comparative study of mental time travel. Trends Cogn Sci 2009, 13: 271-277.

90. Suddendorf T, Busby J. Mental time travel in animals? Trends Cogn Sci 2003, 7:391-396.

91. Williams RA. Are animals stuck in time? Psychol Bull 2002, 128:473-489.

92. Nelson K. Finding one's self in time. In: Snodgrass JG, Thompson RL, eds. Annals of the New York Academy of Sciences: vol. 818. The Self Across Psychology: SelfAwareness, Self-Recognition, and the Self-Concept. New York: New York Academy of Sciences.; 1997, 103-116.

93. Perner J, Ruffman T. Episodic memory and autonoetic consciousness: developmental evidence and a theory of childhood amnesia. J Exper Child Psychol 1994, 59:516-548.

94. Povinelli DJ, Landau KR, Perilloux HK. Selfrecognition in young children using delayed versus live feedback: evidence of a developmental asynchrony. Child Dev 1996, 67:1540-1554.

95. Povinelli DJ, Simon BB. Young children's understanding of briefly versus extremely delayed images of the self: emergence of the autobiographical stance. Dev Psychol 1998, 34:188-194.

96. Hoerl C. On being stuck in time. Phenomenol Cogn Sci 2008, 7:485-500.

97. Beran MJ, Evans TA, Klein ED, Einstein GO. Rhesus monkeys (Macaca mulatta) and capuchin monkeys (Cebus apella) remember future responses in a computerized task. J Exper Psychol Animal Behav Process 2012, 38:233-243.

98. Cheke LG, Clayton NS. Eurasian jays (Garrulus glandarius) overcome their current desires to anticipate two distinct future needs and plan for them appropriately. Biol Lett 2011. doi:10.1098/rsbl.2011.0909.

99. Finn JK, Tregenza T, Norman MD. Defensive tool use in a coconut carrying octopus. Curr Biol 2009, 19:R1069-R1070.

100. Mulcahy NJ, Call J. Apes save tools for future use. Science 2006, 312:1038-1040.

101. In: Fivush R, Haden CA, eds. Autobiographical Memory and the Construction of a Narrative Self. Mahwah, NJ: Lawrence Erlbaum Associates; 2003.

102. In: Fivush R, Haden CA, eds. Remembering and Knowing in Young Children (Emory Symposia in 
Cognition). New York, NY: Cambridge University Press; 2010.

103. Rovee-Collier C. Dissociations in infant memory: rethinking the development of implicit and explicit memory. Psychol Rev 1997, 104:467-498.

104. Suddendorf T, Nielsen M, von Gehlen R. Children's' capacity to remember a novel problem and to secure its future solution. Dev Sci 2011, 14:26-33.

105. In: Bar M, ed. Predictions in the Brain: Using Our Past to Generate a Future. New York, NY: Oxford University Press; 2011.

106. Cheke LG, Clayton NS. Mental time travel in animals. WIREs Cogn Sci 2010, 1:1-16.

107. Nairne JS. The functionalist agenda in memory research. In: Healy AF, ed. Experimental Cognitive Psychology and Its Applications: A Festschriftin honor of Lyle Bourne, Walter Kintsch and Thomas Landaur. Washington, DC: American Psychological Association; 2005.

108. Nairne JS. Adaptive memory: evolutionary constraints on remembering. In: Ross $\mathrm{BH}$, ed. The Psychology of Learning and Motivation, Vol. 53. London: Academic Press; 2010, 1-32.

109. Klein SB, Roberson TE, Delton AW. The futureorientation of memory: planning as a key component mediating the high levels of recall found with survival processing. Memory 2011, 19:121-139.

110. In: Boucher J, Bowler D, eds. Memory in Autism. New York, NY: Cambridge University Press; 2008.

111. Hobson JA, Harris R, Garcia-Perez R, Hobson PR. Anticipatory concern: a study in autism. Dev Sci 2009, 12:249-263.

112. Crane L, Lind SE, Bowler DM. Remembering the past and imagining the future in autistic spectrum disorder. Memory. In press.

113. Kwan D, Craver CF, Green L, Myerson J, Boyer P, Rosenbaum RS. Future decision-making without episodic mental time travel. Hippocampus 2012, 22:1215-1219.

114. Hurley NC, Maguire EA, Vargha-Khadem F. Patient $\mathrm{HC}$ with developmental amnesia can construct future scenarios. Neuropsychologia 2011, 49:3620-3628.

115. Zeithamova D, Schlichting ML, Preston AR. The hippocampus and inferential reasoning: building memories to navigate the future. Front Hum Neurosci 2012, $6: 1-14$.

116. de Vito S, Gamboz N, Brandimonte MA, Barone P, Amboni M, Della Salla S. Future thinking in Parkinson's disease: an executive dysfunction? Neuropsychologia 2012, 50:1494-1501.

117. Arzy S, Collette S, Ionata S, Fornari E, Blanke O. Subjective mental time travel: the functional architecture of projecting the self to the past and future. Eur J Neurosci 2009, 30:2009-2017.
118. Szpunar KK, Tulving E. Varieties of future experience. In: Bar M, ed. Predictions and the Brain: Using our Past to Generate a Future. New York, NY: Oxford University Press; 2011, 3-12.

119. Mooij JJA. Time and Mind. Boston, MA: Brill; 2005.

120. Rochelle G. Behind Time: The Incoherence of McTaggart's a Temporal Replacement. Aldershot, UK: Ashgate; 1998.

121. Loizou A. The Reality of Time. Aldershot: Gower Publishing Co.; 1986.

122. Tallant J. What is B-time? Analysis 2007, 67:147-156.

123. Barbour J. The End of Time. New York, NY: Oxford University Press; 2000.

124. Papa-Grimadli A. Time and Reality. Aldershot: Ashgate; 1998.

125. Friedman WJ. The Developmental Psychology of Time. New York, NY: Academic Press; 1982.

126. Le Poidevin R. The Images of Time: As Essay on Temporal Representation. Oxford: Oxford University Press; 2007.

127. Sherover CM, ed. The Human Experience of Time. New York, NY: New York University Press; 1975.

128. Klein SB, German TP, Cosmides L, Gabriel R. A theory of autobiographical memory: necessary components and disorders resulting from their loss. Social Cogn 2004, 22:460-490.

129. Oshana M. The Importance of How We See Ourselves: Self-Identity and Responsible Agency. Plymouth: Rowman \& Littlefield Publishers; 2010.

130. Tulving E. Episodic and semantic memory. In: Tulving E, Donaldson W, eds. Organization of Memory. New York: Academic Press; 1972, 381-403.

131. Tulving E. Elements of Episodic Memory. New York: Oxford University Press; 1983.

132. Conway MA. Memory and the self. J Mem Lang 2005, 53:594-628.

133. Klein SB, Loftus J. The mental representation of trait and autobiographical Knowledge about the self. In: Srull TK, Wyer RS, eds. Advances in Social Cognition, Vol. 5. Hillsdale, NJ: Erlbaum; 1993, 1-49.

134. Klein SB, Loftus J, Burton HA. Two self-reference effects: the importance of distinguishing between self-descriptiveness judgments and autobiographical retrieval in self-referent encoding. J Person Social Psychol 1989, 56:853-865.

135. Kopelman MD, Wilson BA, Baddeley AD. The autobiographical memory interview: a new assessment of autobiographical and personal semantic memory in amnesic patients. J Clin Exper Neuropsychol 1989, 11: 724-744.

136. Stuss DT, Guzman DA. Severe remote memory loss with minimal anterograde amnesia: a clinical note. Brain Cogn 1988, 8:21-30. 
137. Tulving E, Schacter DL, McLachlan DR, Moscovitch M. Priming of semantic autobiographical knowledge: a case study of retrograde amnesia. Brain Cogn 1988, 8:3-20.

138. Klein SB. The cognitive neuroscience of knowing one's self. In: Gazzaniga MA, ed. The Cognitive Neurosciences III. Cambridge, MA: MIT Press; 2004, 1007-1089.

139. Klein SB. The self: as a construct in psychology and neuropsychological evidence for its multiplicity. WIREs Cogn Sci 2010, 1:172-183.

140. Klein SB, Gangi CE. The multiplicity of self: neuropsychological evidence and its implications for the self as a construct in psychological research. Year Cogn Neurosci 2010 Ann New York Acad Sci 2010, 1191:1-15.

141. Haddock G, Newson M, Haworth J. Do memoryimpaired individuals report stable attitudes? Brit J Soc Psychol 2010, 50:234-245.

142. Haslam C, Jetten J, Haslam SA, Pugliese C, Tonks J. 'I remember therefore I am, and I am therefore I remember': exploring the contributions of episodic and semantic self-knowledge to strength of identity. Brit J Psychol 2010, 102:184-203.

143. Klein SB. The self and its brain. Social Cogn 2012, 30:474-516.

144. Rathbone CJ, Moulin CJA, Conway MA. Autobiographical memory and amnesia: using conceptual knowledge to ground the self. Neurocase 2009, 15:405-418.

145. Klein SB, Lax ML. The unanticipated resilience of trait self-knowledge in the face of neural damage. Memory 2010, 18:918-948.

146. Klein SB. The sense of personal identity. Phenomenol Cogn Sci. In press.

147. Markowitsch HJ, Staniliou A. Memory, autonoetic consciousness, and the self. Conscious Cogn 2011, 20:16-39.

148. Tulving E. What is episodic memory? Curr Direct Psychol Sci 1993, 2:67-70.
149. Faye J. The Reality of the Future. Odense: Odense University Press; 1989.

150. Lieb IC. Past, Present, and Future: A Philosophical Essay about Time. Chicago, IL: University of Illinois Press; 1991.

151. Lockwood M. The Labyrinth of Time. New York, NY: Oxford University Press; 2005.

152. McLure R. The Philosophy of Time. New York, NY: Routledge; 2005.

153. Luria AR. The Man with a Shattered World. Cambridge, MA: Harvard University Press; 1972.

154. Klein SB, Nichols S. Memory and the sense of personal identity. Mind. In press.

155. Talland GA. Self-reference: a neglected component in remembering. Am Psychol 1964, 19:351-353.

156. Sass LA, Parnas J. Schizophrenia, consciousness, and the self. Schizophr Bull 2003, 29:427-444.

157. Oakeley HD. Time and the self in McTaggart's system. Mind 1930, 39: 175-193.

158. Jenkins JJ. Four points to remember: a tetrahedral model of memory experiments. In: Cermak LS, Craik FIM, eds. Levels of Processing in Human Memory. Hillsdale, NJ: Lawrence Erlbaum Publishers; 1979, 429-446.

159. Viard A, Chetelat G, Lebreton K, Desgranges B, Landeau B, de la Sayette V, Eustache F, Piolino P. Mental time travel into the past and the future in healthy aged adults: an fMRI study. Brain Cogn 2011, 75:1-9.

160. Uttal WR. The New Phrenology. Cambridge, MA: MIT Press; 2001.

161. Dumit J. Picturing Personhood: Brain Scans and Personal Identity. Princeton, NJ: Princeton University Press; 2004.

162. Bickle J. Philosophy and Science: A Ruthlessly Reductive Account. Boston, MA: Kluwer Academic Press; 2003.

163. Heisenberg W. Physics and Philosophy. New York, NY: Harper Collins; 1958. 